\title{
Harnup güvesi [Apomyelois (=Ectomyelois) ceratoniae Zeller (Lepidoptera: Pyralidae)]'nin farklı nar çeşitlerindeki bulaşıklık oranı ve konukçu tercihi
}

\author{
Infestation rate and host preference of Carob moth [Apomyelois (=Ectomyelois) \\ ceratoniae Zeller (Lepidoptera: Pyralidae)] on different pomegranate cultivars
}

\author{
Mehmet MAMAY $^{1^{*}}$ Ali IKINCCi ${ }^{2}$ Levent ÜNLÜ $^{3} \quad$ Ergün DOĞAN $^{4}$
}

\begin{abstract}
Summary
This research was conducted in order to determine the infestation rate and host preference of Carob Moth [Apomyelois (=Ectomyelois) ceratoniae Zell. ( Lepidoptera.: Pyralidae)] on 24 years old 13 different pomegranate cultivars under field conditions in 2010 and 2011. In the research, 13 pomegranate cultivars including 3 sour, 5 tartish and 5 sweet planted in $4 \times 4 \mathrm{~m}$ distance were used. The research was carried out on 2 trees of each cultivar from each of 3 replications according to randomized complete block design with 3 replications. In order to determine infestation rate of Carob Moth on different pomegranate cultivars damaged and undamaged harvested fruits were counted and weighed separately at full maturity. Carob Moth infestation rate of each cultivar was determined proportioning infested fruits of the cultivar to all fruits of the same cultivar. In the study, yield, infested and uninfested fruits weight $(\mathrm{kg} / \mathrm{tree})$ of each cultivar were determined individually.

According to the determined average infestation rate of both years, Fellahyemez had the highest average infestation ratio $(51.4 \%)$ followed by Beynarı $(32.59 \%)$, Çekirdeksiz $(31.71 \%)$ and Çevlik $(28.68 \%)$. The infestation rate of Carob Moth on pomegranate cultivars was determined as lesser on sour and tartish tasted cultivars such as Ekşilik (\%3.15), Hicaznar (\%14.04), Mayhoş-I (\%14.24) and Ekşi Göknar (\%17.85). In the study, Beynarı, Hicaznar, Mayhoş-I, Çevlik and Mayhoş-IV were identified as the highest yielding cultivars. In regard to yield and infestation ratio, Hicaznar and Mayhoş-I cultivars had the highest yield and lowest Carob Moth infestation.
\end{abstract}

Key words: Carob Moth, pomegranate, cultivar, infestation rate, host preference

\section{Özet}

$\mathrm{Bu}$ araştırma; Harnup Güvesi'nin [Apomyelois (=Ectomyelois) ceratoniae Zell. ( Lep.: Pyralidae)] arazi koşullarında değişik nar çeşitlerindeki bulaşıklık oranı ve konukçu tercihini belirlemek amacı ile 2010 ve 2011 yıllarında, 24 yaşlı 13 nar çeşidi üzerinde yürütülmüştür. Araştırmada 4 × 4 m mesafede dikilmiş olan 3'ü ekşi, 5'i mayhoş ve 5'i de tatı ılmak üzere toplam 13 çeşit kullanılış̧ır. Araştırma; tesadüf blokları deneme desenine göre, her tekerrürde 2'şer ağaç olmak üzere, 3 tekerrürlü olarak gerçekleştirilmiştir. Harnup Güvesi'nin değişik nar çeşitlerindeki bulaşıklık oranını belirlemek için en uygun olgunlaşma döneminde hasat edilen nar bitkilerine ait meyveler kontrol edilerek, bulaşık olanlar ile sağlam olanlar ayrı ayrı sayılmış ve tartılmıştır. Bulaşık meyve sayısı, ağaçtaki tüm meyve sayısına oranlanarak, Harnup Güvesi'nin o çeşitteki bulaşıklık oranı belirlenmiştir. Çalışmada ayrıca çeşitlerin verimleri, sağlam meyve ve bulaşık meyve ağırlıkları (kg/ağaç) da saptanmıştır.

Her iki yılda tespit edilen bulaşıklık oranı ortalamalarına göre, bulaşıklı̆ın en yüksek olduğu çeşitler $\% 51.40$ ile Fellahyemez, \%32.59 ile Beynarı, \%31.71 ile Çekirdeksiz I ve \% 28.68 ile Çevlik olarak belirlenmiştir. Nar meyvelerinde Harnup Güvesi bulaşıklığının Ekşilik (\%3.15), Hicaznar (\%14.04), Mayhoş I (\%14.24) ve Ekşi Göknar (\%17.85) gibi ekşi ve mayhoş tada sahip olan çeşitlerde daha az oranda görüldüğü saptanmışıtır. Çalışmada Beynarı, Hicaznar, Mayhoş I, Çevlik ve Mayhoş IV çeşitleri yüksek verimli çeşitler olarak tespit edilmiştir. Çeşitlerdeki Harnup Güvesi zararı ve çeşitlerin bitki başına ortalama verim değerleri birlikte değerlendirildiğinde, Hicaznar ve Mayhoş I çeşitlerinin az bulaşık ve yüksek verimli çeşitler olduğu belirlenmiştir.

Anahtar sözcükler: Harnup Güvesi, nar, çeşit, bulaşıklık oranı, konukçu tercihi

\footnotetext{
${ }^{1}$ Gıda Tarım ve Hayvancılık İı Müdürlüğü, 63100, Şanlıurfa

${ }^{2}$ Harran Üniversitesi Ziraat Fakültesi Bahçe Bitkileri Bölümü, 63000, Osmanbey, Şanlıurfa

${ }^{3}$ Selçuk Üniversitesi Ziraat Fakültesi Bitki Koruma Bölümü, 42100, Selçuklu, Konya

${ }^{4}$ İnönü Üniversitesi Ziraat Fakültesi Bahçe Bitkileri Bölümü, 44280, Malatya.

*Sorumlu yazar (Corresponding author) e-mail: mehmetmamay@hotmail.com

Alınış (Received): 13.11.2013 Kabul ediliş (Accepted): 17.02.2014
} 


\section{Giriş}

Nar (Punica granatum L.), 6500 yıldır insanoğlunun bildiği, yediği ve şifa kaynağı kabul ettiği bilinen en eski meyve türlerinden biri olup, anavatanları İran, Hindistan, Afganistan, Anadolu, Güney Asya, Yakın Doğu, Orta Doğu ve Güney Kafkasya arasındaki bölgeleri kapsamaktadır (Onur, 1988; İkinci, 2007). Nar, kurak iklim koşullarına dayanıkı, farklı toprak yapısına kısa zamanda uyum sağlayabilen ve her yıl düzenli ürün veren bir bitkidir (Özgüven \& Yılmaz, 2000). Dünyada Hindistan (1.140.000 ton), İran (705.000 ton) ve Türkiye (217.572 ton) önemli nar üreticisi ülkelerdir (Anonymous, 2012a). Nar, Türkiye'de hemen hemen her bölgede yetiştirilmesine karşın, özellikle Ege ve Akdeniz sahil şeridinde ve Güneydoğu Anadolu'da yaygın olarak yetiştirilmektedir (Özgüven \& Yılmaz, 2000). Ülkemizde nar üretiminin en fazla olduğu ilk üç il İçel, Antalya ve Hatay'dır (Yazıcı \& Şahin, 2012). Türkiye, narın anavatanı sınırları içinde olması nedeniyle, büyük ölçüde çeşit ve form zenginliği göstermektedir. Ülkemizde hâlihazırda yetiştirilen yöresel tipler dışında, 48 adet tescilli ve üç adet üretim izinli nar çeşidi bulunmaktadır (Anonymous, 2012b).

Yetiştiriciliği yapılan diğer meyve türlerinde olduğu gibi, nar bitkisinde de ürün kaybına neden olan birçok zararlı böcek ve akar türü bulunmaktadır. Nar yetiştiriciliği yapılan ülkelerde (Arutyunyan, 1990; Zare et al., 2013) ve ülkemizin diğer bölgelerinde olduğu gibi Güneydoğu Anadolu Bölgesi'ndeki narların en önemli zararlısı Harnup Güvesi [Apomyelois (=Ectomyelois) ceratoniae Zell. ( Lep.: Pyralidae)]'dir. (Mart \& Kılınçer, 1993; Mart \& Kılınçer, 1994; Öztürk et al., 2005; Öztürk \& Ulusoy, 2009; Öztop et al., 2010). Yurtdışında ve ülkemizde yapılan çalışmalarda, yılda 4-5 döl verdiği tespit edilen $A$. ceratoniae'nin ilk erginlerinin iklime bağlı olarak nisan-haziran aylarında uçmaya başladıkları belirlenmiştir (Gothilf, 1970; Kashkuli \& Eghtedar, 1976; Mart \& Kılınçer, 1993; Toledo \& Albujer, 2005; Öztürk \& Ulusoy, 2011; Mamay, 2013). Türkiye'de, Akdeniz ve Güneydoğu Anadolu bölgelerinde yürütülen araştırmalarda, $A$. ceratoniae'nin ergin uçuşunun kasım ayı içerisinde son bulduğu tespit edilmiştir (Mart, 1992; Mart \& Kılınçer, 1993; Öztop et al., 2010; Öztürk \& Ulusoy, 2011; Mamay, 2013). Polifag bir meyve zararlısı olan Harnup Güvesi'nin konukçuları arasında keçiboynuzu, nar, hurma, trabzonhurması, yenidünya, turunçgiller, ceviz, elma, armut, badem, kestane, fındık, üzüm, incir, antepfıstığı ve zeytin bulunmaktadır (Avidov \& Gothilf, 1960; Tokmakoğlu et al., 1967; Balachowsky, 1972; Echlin, 1982; Al-Izzi et al., 1985; Mehrnejad, 1993; Mozaffarian et al., 2007b; Norouzi, 2008).

Harnup Güvesi, nar meyvelerini kurtlandırarak çürümesine ve dolayısıyla da pazar değerinin düşmesine neden olmaktadır (Tokmakoğlu et al., 1967; Mart, 1992; Mozaffarian et al., 2007a; Norouzi, 2008). Zararlı, kışı larva döneminde ağaç üzerindeki çürümüş nar meyveleri içinde, yere dökülmüş meyvelerde, ağaç kabuklarının altlarında veya çatlaklarda geçirmektedir. Harnup Güvesi'nin ilk ergin çıkışı, nar çiçek döneminde (nisan-haziran ayları arasında) olduğundan ilk dölünün nar meyvelerinde zararı söz konusu değildir (Mehrnejad, 1993; Mozaffarian et al., 2007a). Yumurtalarını temmuz ayından itibaren ben düşme dönemindeki narların meyve tacına (kaliks) genellikle tek tek bırakmakta ve yumurtadan çıkan larvalar ilk önce narın meyve tacında, daha sonra ise meyveye girerek tanelerde beslenmektedir (Mart, 1992; Mart \& Kılınçer, 1993; Öztürk \& Ulusoy, 2011). Bu şekilde zarar gören narların dış kabuğunda önce kahverengileşerek çökme olmakta, meyvenin içi tamamen siyahlaşarak küflenmekte ve daha sonra meyvenin tamamı çürümektedir. Şanlıurfa'da bazı bahçelerde bulaşıklık oranının \%80'lerin üzerine çıktığı bu zararının kimyasal mücadelesinde başarı şansının düşük olduğu, alternatif bir mücadele yöntemi olarak çiftleşmeyi engelleme tekniğinin $62.5 \mathrm{~g} / \mathrm{da}$ dozunda, mekanik mücadele ve hasada yakın dönemde yapılacak bir bioinsektisit uygulaması ile birleştirilmesi durumunda başarılı sonuçların elde edilebildiği yapılan bir araştırma ile ortaya çıkarılmıştır (Mamay, 2013).

Harnup Güvesi'nin Türkiye'deki tescilli nar çeşitleri arasındaki tercihini ortaya çıkaran herhangi bir çalışma yapılmadığından özgün bir araştırma olarak bu çalışmada, Harnup Güvesi'nin nar çeşitleri arasında bir tercihinin olup olmadığı, aynı zamanda bu çeşitlerden hem Harnup Güvesi'ne dayanıklı hem de yüksek verimli olanlarının belirlenerek üreticilere tavsiye edilmesi amaçlanmıştır. 


\section{Materyal ve Metot}

\section{Materyal}

Çalışma, Şanlıurfa il merkezinden 34 km uzaklıktaki GAP Tarımsal Araştırma Enstitüsü Müdürlüğü Talat Demirören İstasyonu'nda (36 $54^{\prime} \mathrm{N}$; 38 $8^{\circ} 55^{\prime} \mathrm{E}$ koordinatlarında ve $410 \mathrm{~m}$ rakımda) 1986 yılında 21 nar çeşidine ait fidanlarla $4 \times 4 \mathrm{~m}$ mesafede dikilmiş ve her çeşide ait 10 ağaç olan nar adaptasyon bahçesinde 2010-2011 yıllarında yürütülmüştür. Çalışma süresince, denemenin kurulduğu bahçede sulama, budama ve gübreleme işlemleri standart olarak gerçekleştirilmiştir.

Çalışmanın ana materyalini, Adana, Antalya, Hatay ve İçel illerinden selekte edilmiş olan toplam 13 yerli nar çeşidi ve Harnup Güvesi oluşturmuştur. Çalışmada; 3'ü ekşi, 5'i mayhoş ve 5'i de tatlı olan çeşitler kullanılmıştır. Çalışmada kullanılan nar çeşitlerine ait özellikler Çizelge 1'de verilmiştir (Onur et al., 1999; Özgüven \& Yılmaz, 2000; Polat \& Özer, 2000; Uzun et al., 2007; Ak et al., 2009).

Çizelge 1. Çalışmada kullanılan nar çeşitlerine ait bazı pomolojik özellikler

\begin{tabular}{|c|c|c|}
\hline $\begin{array}{l}\text { Sira } \\
\text { No }\end{array}$ & Çeşit Adı & Meyve Özellikleri \\
\hline 1 & Adsız (31 N 11) & $\begin{array}{l}\text { Sarı zemin üzerinde kırmızı kabuklu, yumuşak çekirdekli, iri daneli ve orta mevsimde olgunlaşan } \\
\text { tatlı bir çeşit. }\end{array}$ \\
\hline 2 & Aşınar (33 N 11) & Beyaz ve orta sert daneli ve ekşic bir çeşit. \\
\hline 3 & Beynarı (33 N 24) & $\begin{array}{l}\text { Yeşilimsi sarı kabuk renginde, iri meyveli, orta sert çekirdeklere sahip, yüksek verimli, orta } \\
\text { mevsimde olgunlaşan tatlı meyveli bir çeşit. }\end{array}$ \\
\hline 4 & Çekirdeksiz I (07 N 01) & Yumuşak çekirdekli ve tatı bir çeşit. \\
\hline 5 & Çevlik (33 N 23) & Sarı zemin üzerinde kırmızı kabuklu, meyvesi orta irilikte, orta sert daneli, geççi ve tatı bir çeşit. \\
\hline 6 & Ekşi Göknar (33 N 12) & $\begin{array}{l}\text { Yeşil sarı üzerinde kırmızı kabuklu, orta sert çekirdekli, meyve suyuna uygun, geççi ve ekşi tada } \\
\text { sahip çeşit. }\end{array}$ \\
\hline 7 & Ekşilik (01 N 07) & Kuru madde miktarı düşük, asit oranı yüksek, geççi ve ekşi bir çeşit. \\
\hline 8 & Fellahyemez (01 N 04) & $\begin{array}{l}\text { Sarı kabuklu, beyaz daneli, } 100 \text { dane ağırlığı ve dane randımanı açısından çok iyi, geççi ve tatlı } \\
\text { bir çeşit. }\end{array}$ \\
\hline 9 & Hicaznar (07 N 08) & $\begin{array}{l}\text { Kırmızı kabuklu, iri meyveli, koyu kırmızı ve orta sert daneli, yüksek verimli, hem meyve suyu } \\
\text { hem de sofralığa uygun, muhafazası kolay, geççi ve mayhoş bir çeşit. }\end{array}$ \\
\hline 10 & Katırbaşı (31 N 07) & $\begin{array}{l}\text { Kabuk rengi sarımsı pembe, pembe daneli, çekirdekler orta sert, geççi, mayhoş ve dane } \\
\text { randımanı düşük bir çeşit. }\end{array}$ \\
\hline 11 & Mayhoş I (33 N 09) & $\begin{array}{l}\text { Yeşilimsi sarı üzerine kırmızı renkli, orta-sert çekirdekli, yüksek verimli, usarelik, orta mevsim ve } \\
\text { ekşimsi-mayhoş tada sahip bir çeşit. }\end{array}$ \\
\hline 12 & Mayhoş VI (33 N 49) & $\begin{array}{l}\text { Sarımsı pembe kabuk renginde, iri meyveli, orta sert daneli, dane randımanı düşük, geççi ve } \\
\text { mayhoş-tatlı bir çeşit. }\end{array}$ \\
\hline 13 & Silifke Aşısı (33 N 16) & $\begin{array}{l}\text { Sarı zemin üzerinde açık pembe kabuk renginde, iri meyveli, orta sert daneli, geççi ve mayhoş } \\
\text { tada sahip bir çeşit. }\end{array}$ \\
\hline
\end{tabular}

\section{Metot}

Araştırmanın yürütüldüğü bahçede, fungal ve bakteriyel hastalıklara karşı kış ilaçlaması olarak biri bitkilerin yapraklarının \% 75'inin döküldüğü dönemde (aralık ayı), diğeri de budama işleminden hemen sonra olmak üzere her yıl \% 2'lik bordo bulamacı uygulaması yapılmıştır. Her yıl ağaçlarda ilk yaprakların görülmeye başlandığı dönem ile çiçeklenmenin başladığı dönem arasında yaprak bitine karşı mayıs ayı içerisinde 2 hafta ara ile birer kez Acetamiprid \%20 SP. Thiamethoxam $240 \mathrm{~g} / \mathrm{L} \mathrm{SC}$ etkili maddeli insektisitlerle münavebeli olarak ilaçlama yapılmıştır. Her yıl Harnup güvesine karşı temmuz ayı başından 
Harnup güvesi [Apomyelois (=Ectomyelois) ceratoniae Zeller (Lepidoptera: Pyralidae)]'nin farklı nar çeşitlerindeki bulaşıklık oranı ve konukçu tercihi

itibaren yaklaşık 20 gün arayla 3 kez Bacillus thuringiensis intiva eden farklı firmalara ait bir bioinsektisit ile ilaçlamalar yapılmıştır (Mart \& Kılınçer, 1994).

Harnup Güvesi'nin farklı nar çeşitlerindeki bulaşıklık oranını belirlemek için hasattan yaklaşık 1 hafta önce, bitki gelişimi, gövde sayısı ve meyve tutum oranı da dikkate alınarak, tesadüfi olarak, her çeşide ait toplam 6 ağaç seçilerek işaretlenmiştir. Nar bitkisinde genel olarak hasadın 2-3 defada yapılması önerilmektedir (İkinci, 2007). Araştırmada, nar çeşitlerine ait bitkiler, 15 gün arayla olmak üzere 2 defada hasat edilmiştir. Her çeşide ait önceden işaretlenmiş olan bitkilerden, birinci ve ikinci hasat dönemlerinde makasla saplarından kesilerek plastik kasalara toplanan nar meyvelerinin kasaları üzerine çeşit ve tekerrür bilgileri yazılı etiketler konulmuştur. Birinci hasat döneminde, bitki üzerindeki Harnup Güvesi zararına uğramış tüm meyveler hasat edilmiştir. Harnup Güvesi zararı nedeniyle yere dökülmüş olan meyveler de hesaplamalara dâhil edilmiştir. Tüm çeşitlere ait birinci hasat işlemi bittikten sonra, her kasadaki sağlam ve Harnup Güvesi ile bulaşık olan meyveler ayrılmış, daha sonra bu meyveler ayrı olarak sayılmıştır. Bu işlemlerden sonra, kasalardaki sağlam meyveler ve Harnup Güvesi ile bulaşık olan meyveler tartılarak kaydedilmiştir. Birinci hasattaki benzer işlem adımları ikinci hasatta da uygulanmıştır. İkinci hasat işleminde belirlenen tartım ve sayım sonuçları, daha önceki rakamlara ilave edilmiştir.

Harnup Güvesi, Şanlıurfa ilinde yetiştirilen narların ana zararısı konumundadır. Harnup Güvesi'nin meyvedeki zarar belirtisi çok tipik olduğu için, bulaşık olarak tespit edilen meyvelerdeki zararın, başka bir zararının zararıyla karıştıııması söz konusu değildir. Yapılan bulaşık meyve sayımlarında, zarar belirtisinin yanında, üzerinde Harnup Güvesi'nin yumurta ve larvası bulunan nar meyveleri de bulaşık kabul edilmiştir. Nar çeşitlerine ait ağaçlardan elde edilen sağlam ve bulaşık meyve sayımları verilerine dayanarak çeşitlere göre zarar oranı; "bulaşık meyve oranı $(\%)=($ bulaşık meyve sayısı $x 100) /$ toplam meyve sayısı" formülü ile hesaplanmıştır.

Çalışma, tesadüf blokları deneme desenine göre, 2 ağaç 1 tekerrür olacak şekilde, 3 tekerrürlü olarak yürütülmüştür. Çeşitlerin hepsi Harnup Güvesi zararına açık olduğundan ve aynı uygulamalara maruz kaldığından kontrol grupları seçilmemiştir. Çeşitlerin Harnup Güvesi zararına uğrama oranları tek yönlü varyans analizi ile belirlenmiş, yüzde (\%) olarak elde edilen değerlere açı transformasyonu uygulanmış, çeşitler arasındaki önemli farklılıklar ise Minitab 16.1 .0 istatistik programı kullanılarak Duncan çoklu karşılaştırma testine göre $p<0.05$ düzeyinde analiz edilmiştir.

\section{Araştırma Sonuçları ve Tartışma}

Harnup Güvesinin değişik nar çeşitlerinde tespit edilen bulaşıklık oranları, bulaşık meyve ağırlıkları ve verim değerlerine ilişkin varyans analiz sonuçları Çizelge 2'de verilmiştir.

Harnup Güvesinin değişik nar çeşitlerinde saptanan bulaşıklık oranları arasında \% 0.1 düzeyinde önemli farklılık olduğu tespit edilmiştir. Harnup Güvesi bulaşıklığının 2010 yılında en fazla görüldüğü çeşitler; \% 46.73 bulaşıklık oranı ile Fellahyemez, \% 31.41 bulaşıklık oranı ile Beynarı ve \% 29.41 bulaşıklık oranı ile Çekirdeksiz I çeşitleri olduğu tespit edilmiştir (Çizelge 3). Aynı yıl Harnup Güvesi bulaşıklığının en az oranda görüldüğü çeşitler ise \% 3.30 bulaşıklık oranı ile Ekşilik, \% 13.08 bulaşıklık oranı ile Hicaznar ve \% 13.48 bulaşıklık oranı ile Mayhoş I çeşitleri olmuştur. Diğer çeşitlerdeki bulaşıklık oranları ise bu iki grup arasında yer almışlardır (Çizelge 3).

Harnup Güvesi'nin 2011 yılında değişik nar çeşitlerindeki bulaşıklık oranı sonuçları, 2010 yılı sonuçlarıyla oldukça paralellik göstermiştir. Bu yılda Harnup Güvesi ile bulaşıklık oranının en yüksek olduğu çeşitler; Fellahyemez, Çekirdeksiz I, Beynarı ve Katırbaşı çeşitleri olmuştur. Bu çeşitlerdeki bulaşıklık oranları sırasıyla; \% 56.07, \% 34.00, \% 33.76 ve \% 33.00 olarak belirlenmiştir. Bu yılda da, 2010 yılında elde edilmiş sonuçlara benzer olarak, Harnup Güvesi zararının en az görüldüğü çeşitler; Ekşilik, Hicaznar, Mayhoş I ve Ekşi Göknar olarak tespit edilmiştir. Bu çeşitlerdeki zarar oranları sırasıyla; \% 3.00, \% 15.00, \%15.00 ve \% 19.25 olarak saptanmıştır (Çizelge 3). 
İki yıllık bulaşıklık oranı ortalamalarına göre, en yüksek bulaşık meyve oranı \% 51.40 ile Fellahyemez, en düşük bulaşık meyve oranı ise \% 3.15 ile Ekşilik çeşitlerinde belirlenmiştir. Yıllara göre Harnup Güvesi'nin değişik nar çeşitlerindeki bulaşıklık oranları arasındaki farklılık önemli bulunmuştur. Tüm nar çeşitlerinin ortalamasına göre, 2011 yılında tespit edilen Harnup Güvesi bulaşıklık oranının (\% 26.75), 2010 yılındaki bulaşıkııı̆a (\%22.69) göre daha yüksek olduğu belirlenmiştir (Çizelge 3).

Çizelge 2. Şanlıurfa ilinde 2010 ve 2011 yıllarında farklı nar çeşitlerinde Harnup Güvesi (Apomyelois ceratoniae) zararına ilişkin saptanan çeşitli özelliklere ait varyans analiz sonuçları

\begin{tabular}{lllll}
\hline & SD & \multicolumn{3}{c}{ F- Değerleri } \\
\cline { 3 - 5 } $\begin{array}{l}\text { Varyasyon } \\
\text { Kaynakları }\end{array}$ & & $\begin{array}{c}\text { Bulaşık meyve } \\
\text { oranı }\end{array}$ & $\begin{array}{c}\text { Bulaşık meyve } \\
\text { ağırlığı }\end{array}$ & Verim \\
\hline Çeşit $(C ̧)$ & 12 & $480.484^{* * *}$ & $130.285^{* * *}$ & $44.354^{* * *}$ \\
\hline Yıl $(Y)$ & 1 & $151.829^{* * *}$ & $99.902^{* * *}$ & $16.719^{*}$ \\
\hline Ç $\times Y$ & 12 & $7.892^{* * *}$ & $3.717^{* * *}$ & 0.3338 Ö.D. \\
\hline Hata & 50 & & & \\
\hline
\end{tabular}

*: \% 5 düzeyinde önemli; *** \% 0.1 düzeyinde önemli; Ö.D.: Önemli değil

Araştırma bahçesindeki nar çeşitlerinde 2010 ve 2011 yıllarında elde edilen verim değerleri bakımından önemli farklıııklar saptanmıştır (Çizelge 2-4). Nar çeşitlerinde tespit edilen ortalama verim değerlerine göre ağaç başına en yüksek verimler; Beynarı $(75.67 \mathrm{~kg})$, Hicaznar $(74.50 \mathrm{~kg})$ ve Mayhoş I $(69.00 \mathrm{~kg})$ çeşitlerinden elde edilmiştir. Bu çeşitlerde tespit edilen bulaşık meyve ağırıkları ise sırasıyla; 24.69, 10.51 ve $9.84 \mathrm{~kg}$ olarak belirlenmiştir (Çizelge 5).

Çizelge 3. Şanlıurfa ilinde 2010 ve 2011 yıllarında farklı nar çeşitlerinde Harnup Güvesi (Apomyelois ceratoniae)'nin bulaşıklık oranı

\begin{tabular}{clrcr}
\hline $\begin{array}{c}\text { Sıra } \\
\text { No }\end{array}$ & & Çeşit & \multicolumn{3}{c}{ Bulaşıklık Oranı (\%) } \\
\cline { 3 - 5 } 1 & Adsız & 2010 & 2011 & Ortalama \\
\hline 2 & Aşınar & $26.14 \mathrm{~d}$ & $28.00 \mathrm{de}$ & $27.07 \mathrm{~cd}$ \\
3 & Beynarı & $31.41 \mathrm{~b}$ & $33.76 \mathrm{bc}$ & $32.59 \mathrm{~b}$ \\
4 & Çekirdeksiz-I & $29.41 \mathrm{bc}$ & $34.00 \mathrm{~b}$ & $31.71 \mathrm{~b}$ \\
5 & Çevlik & $26.66 \mathrm{c}$ & $30.65 \mathrm{~cd}$ & $28.66 \mathrm{c}$ \\
6 & Ekşi Göknar & $16.45 \mathrm{f}$ & $19.25 \mathrm{~g}$ & $17.85 \mathrm{f}$ \\
7 & Ekşilik & $3.30 \mathrm{~h}$ & $3.00 \mathrm{i}$ & $3.15 \mathrm{~h}$ \\
8 & Fellahyemez & $46.73 \mathrm{a}$ & $56.07 \mathrm{a}$ & $51.40 \mathrm{a}$ \\
9 & Hicaznar & $13.08 \mathrm{~g}$ & $15.00 \mathrm{~h}$ & $14.04 \mathrm{~g}$ \\
10 & Katırbaşı & $24.26 \mathrm{~d}$ & $33.00 \mathrm{bc}$ & $28.63 \mathrm{c}$ \\
11 & Mayhoş-ı & $13.48 \mathrm{~g}$ & $15.00 \mathrm{~h}$ & $14.24 \mathrm{~g}$ \\
12 & Mayhoş-Vı & $24.74 \mathrm{~d}$ & $27.00 \mathrm{e}$ & $25.87 \mathrm{~d}$ \\
13 & Silifke Aşısı & $19.25 \mathrm{e}$ & $22.00 \mathrm{f}$ & $20.63 \mathrm{e}$ \\
& Yıl ortalaması & $22.69 \mathrm{~B}$ & $26.75 \mathrm{~A}$ & \\
\hline
\end{tabular}

*Aynı sütunda bulunan ve farklı harflerle işaretlenen değerler arasında $\mathrm{P}<0.05$ önem seviyesinde fark bulunmaktadır.

** Büyük harfler yatay, küçük harfler düşey karşılaştırma içindir. 
Harnup güvesi [Apomyelois (=Ectomyelois) ceratoniae Zeller (Lepidoptera: Pyralidae)]'nin farklı nar çeşitlerindeki bulaşıklık oranı ve konukçu tercihi

Çizelge 4. Şanlıurfa ilinde farklı nar çeşitlerinde 2010 ve 2011 yıllarında tespit edilen verim değerleri

\begin{tabular}{cllll}
\hline \multirow{2}{*}{ Sıra No } & \multirow{2}{*}{ Çeşit } & \multicolumn{3}{c}{ Verim (kg/ağaç) } \\
\cline { 3 - 5 } & & 2010 & \multicolumn{3}{c}{2011} & Ortalama \\
\hline 1 & Adsız & $67.00 \mathrm{abc}$ & $69.00 \mathrm{~cd}$ & $68.00 \mathrm{c}$ \\
2 & Aşınar & $65.00 \mathrm{bc}$ & $65.00 \mathrm{cde}$ & $65.00 \mathrm{~cd}$ \\
3 & Beynarı & $73.00 \mathrm{a}$ & $78.33 \mathrm{a}$ & $75.67 \mathrm{a}$ \\
4 & Çekirdeksiz-I & $41.00 \mathrm{f}$ & $44.00 \mathrm{~h}$ & $42.50 \mathrm{~h}$ \\
5 & Çevlik & $67.00 \mathrm{abc}$ & $70.00 \mathrm{bc}$ & $68.50 \mathrm{c}$ \\
6 & Ekşi Göknar & $58.00 \mathrm{de}$ & $62.33 \mathrm{def}$ & $60.17 \mathrm{de}$ \\
7 & Ekşilik & $53.33 \mathrm{e}$ & $56.00 \mathrm{fg}$ & $54.67 \mathrm{fg}$ \\
8 & Fellahyemez & $52.00 \mathrm{e}$ & $54.00 \mathrm{~g}$ & $53.00 \mathrm{~g}$ \\
9 & Hicaznar & $72.00 \mathrm{ab}$ & $77.00 \mathrm{ab}$ & $74.50 \mathrm{ab}$ \\
10 & Katırbaşı & $56.00 \mathrm{e}$ & $60.00 \mathrm{efg}$ & $58.00 \mathrm{ef}$ \\
11 & Mayhoş-I & $67.00 \mathrm{abc}$ & $71.00 \mathrm{abc}$ & $69.00 \mathrm{bc}$ \\
12 & Mayhoş-VI & $68.00 \mathrm{abc}$ & $69.00 \mathrm{~cd}$ & $68.50 \mathrm{c}$ \\
13 & Silifke Aşısı & $63.00 \mathrm{~cd}$ & $68.00 \mathrm{~cd}$ & $65.50 \mathrm{c}$ \\
\hline
\end{tabular}

*Aynı sütunda bulunan ve farklı harflerle işaretlenen değerler arasında $P<0.05$ önem seviyesinde fark bulunmaktadır. ** Büyük harfler yatay, küçük harfler düşey karşılaştırma içindir.

Araştırmada, iki yıllık değerlerin ortalamasına göre Harnup Güvesi ile en yüksek bulaşık meyve oranları \% 51.40 ile Fellahyemez, \% 32.59 ile Beynarı ve \% 31.71 ile Çekirdeksiz I çeşitlerinde tespit edilmiştir (Çizelge 3). Bu çeşitlerde sırasıyla; $53.00,75.67$ ve $42.50 \mathrm{~kg}$ ortalama verim değerlerinin, 27.31, 24.69 ve 13.53 kg'ının Harnup Güvesi ile bulaşık olduğu belirlenmiştir (Çizelge 4 ve 5).

Çizelge 5. Şanlıurfa ilinde 2010 ve 2011 yıllarında farklı nar çeşitlerinde tespit edilen Harnup Güvesi (Apomyelois ceratoniae) zararına uğramış bulaşık meyve miktarı

\begin{tabular}{llccc}
\hline \multirow{2}{*}{$\begin{array}{l}\text { Sıra } \\
\text { No }\end{array}$} & Çeşit & \multicolumn{3}{c}{ Bulaşık meyve miktarı (kg/ağaç) } \\
\cline { 3 - 5 } & Adsız & $13.45 \mathrm{c}$ & $21.40 \mathrm{~b}$ & $17.42 \mathrm{c}$ \\
\hline 1 & Aşınar & $16.99 \mathrm{~b}$ & $18.20 \mathrm{c}$ & $17.59 \mathrm{bc}$ \\
3 & Beynarı & $22.94 \mathrm{a}$ & $26.45 \mathrm{a}$ & $24.69 \mathrm{a}$ \\
4 & Cekirdeksiz-ı & $12.09 \mathrm{~cd}$ & $14.97 \mathrm{~d}$ & $13.53 \mathrm{~d}$ \\
5 & Cevlik & $17.86 \mathrm{~b}$ & $21.46 \mathrm{~b}$ & $19.66 \mathrm{~b}$ \\
6 & Ekşi Göknar & $9.54 \mathrm{de}$ & $12.01 \mathrm{e}$ & $10.78 \mathrm{e}$ \\
7 & Ekşilik & $1.76 \mathrm{f}$ & $1.68 \mathrm{f}$ & $1.72 \mathrm{f}$ \\
8 & Fellahyemez & $24.30 \mathrm{a}$ & $30.31 \mathrm{a}$ & $27.31 \mathrm{a}$ \\
9 & Hicaznar & $9.46 \mathrm{de}$ & $11.56 \mathrm{e}$ & $10.51 \mathrm{e}$ \\
10 & Katırbaşı & $13.60 \mathrm{c}$ & $19.79 \mathrm{bc}$ & $16.69 \mathrm{c}$ \\
11 & Mayhoş-ı & $9.04 \mathrm{e}$ & $10.65 \mathrm{e}$ & $9.84 \mathrm{e}$ \\
12 & Mayhoş-Vı & $16.82 \mathrm{~b}$ & $18.64 \mathrm{bc}$ & $17.73 \mathrm{bc}$ \\
13 & Silifke Așısı & $12.14 \mathrm{~cd}$ & $14.94 \mathrm{~d}$ & $13.54 \mathrm{~d}$ \\
\hline Yıl ortalaması & $13.85 \mathrm{~B}$ & $17.08 \mathrm{~A}$ & \\
\hline
\end{tabular}

*Aynı sütunda bulunan ve farklı harflerle işaretlenen değerler arasında $P<0.05$ önem seviyesinde fark bulunmaktadır.

** Büyük harfler yatay, küçük harfler düşey karşılaştırma içindir.

Bu çalışmanın asıl amacı, Harnup Güvesi'ne dayanıklı ve duyarlı çeşitleri belirlemek ve mücadelesi oldukça zor olan bu zararlı ile az bulaşık çeşitleri üreticilere tavsiye etmektir. Ancak, bir çeşidi üreticilere tavsiye ederken sadece Harnup Güvesi'ne karşı dayanıklılığına göre hareket etmek doğru olmayacaktır. Burada, çeşidin meyve veriminin, bulaşıklık değerleriyle birlikte karşılaştırılması yararlı olacaktır. Çeşitlerden elde edilen verim değerlerinin ortalamalarına ve Harnup Güvesi ile bulaşık olan meyve 
ağırığına göre hazırlanan Şekil 1'de, hangi çeşitlerin yüksek verimli ve hangi çeşitlerin ise Harnup Güvesi tarafından daha çok tercih edildiği kolaylıkla görülmektedir.

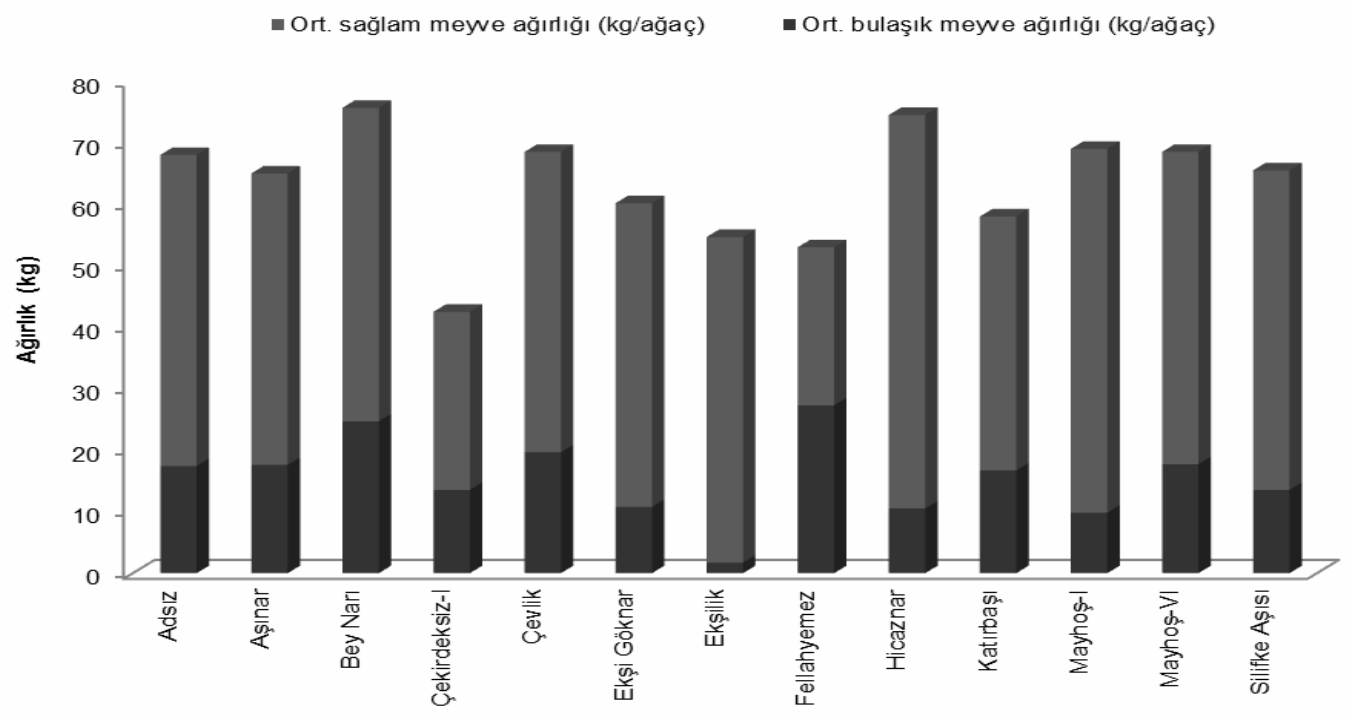

Şekil 1. Şanlıurfa ilinde farklı nar çeşitlerinde 2010 ve 2011 yıllarında tespit edilen ortalama sağlam ve bulaşık meyve miktarları.

Çalışma sonunda elde edilen iki yıllık veriler birlikte değerlendirildiğinde, Harnup Güvesi zararına en az uğrayan çeşitlerin; Ekşilik, Hicaznar, Mayhoş I ve Ekşi Göknar çeşitleri olduğu tespit edilmiştir. Bu çeşitlerin verim durumlarına bakıldığında (Çizelge 4), tüm çeşitlerin ortalama verimlerinin üzerinde bir verime sahip oldukları görülmektedir. Aynı çeşitler tat ve meyve asitlik değerlerine göre karşılaştırıldıklarında; Ekşilik ve Ekşi Göknar çeşitlerinin çok ekşi, Hicaznar ve Mayhoş I çeşitlerinin ise titre edilebilir asit oranlarının yüksek olması nedeniyle, ekşiye yakın mayhoş tada sahip oldukları bilinmektedir (Polat \& Özer, 2000; Ak et al., 2009).

Çalışmada Fellahyemez, Beynarı, Çekirdeksiz I ve Çevlik çeşitleri hem 2010 yılında hem de 2011 yılında, bulaşıklığın en yüksek olduğu çeşitler olarak belirlenmiştir (Çizelge 3). Harnup Güvesi ile bulaşıklık oranı yüksek olan bu çeşitlerin tamamı tatı tada (Yılmaz et al., 1993; Özgüven et al., 1997; Polat \& Özer, 2000; Uzun et al., 2007; Ak et al., 2009) sahiptir (Çizelge 1). Ayrıca hem 2010 hem de 2011 yılında Harnup Güvesi bulaşıklık oranı daha yüksek olan aynı çeşitlerin kabuk renklerine (Polat \& Özer, 2000; Ak et al., 2009) bakıldığında; sarı, yeşilimsi sarı veya sarımsı pembe gibi açık renk tonlarına sahip olduğu, ancak; kırmızı veya kırmızıya yakın koyu tonlarda olmadıkları saptanmıştır (Çizelge 1). Bazı nar çeşit ve tiplerinin Gaziantep yöresine adaptasyonu ile ilgili yapılan bir çalışmada, Fellahyemez çeşidinin bu çalışmaya paralel olarak Harnup Güvesi'nden çok zarar gördüğü bildirilmiştir (Uzun et al., 2007).

Şanlıurfa'nın değişik yörelerindeki nar bahçelerinde yapılan arazi çalışmaları neticesinde Hicaznar çeşidinin, yerel nar tiplerine (Suruç narı, Siverek narı v.s.) nazaran Harnup Güvesi tarafından daha az tercih edilen bir çeşit olduğu görülmektedir. Harnup Güvesi'nin nar çeşitlerine yönelik tercihinin kabuk kalınlığı veya kabuğun sertliği ile de yakından ilgili olduğu düşünülmektedir. Bu nedenle, nar çeşitlerinin kabuk sertlikleri veya kalınlıkları ile Harnup Güvesi zararı arasında ters bir ilişki olduğu düşünülmektedir. Nitekim bu çalışmada, Narda Kahverengi Leke [(Alternaria alternata (Fr.) Keissı.)] hastalığından dolayı 
nar meyvesinde kabuğun sert, kuru ve mat bir hal almasından dolayı Harnup Güvesi larvasının bu tür meyvelere giriş yapamadığı, benzer çalışmalarda da Harnup Güvesi larvasının meyveye giriş yaptığı yerin, nispeten yumuşak olan kaliksten (taç kısmı) olduğu (Mart \& Kılınçer, 1993) anlaşılmaktadır. Bu çalışmada, Harnup güvesi zararının az olduğu belirlendiği çeşitlerde ortak bir özelliğin de nispeten kalın kabuklu olmaları bu düşünceyi kuvvetlendirmektedir.

Böceklerin, konukçu üzerine koymuş oldukları yumurtadan, ergin bir böceğin meydana geliş süresinin kısalığına ve bir konukçu üzerine toplamda daha fazla yumurta koyma uygunluğuna göre, konukçu bitkiler arasında seçim yaptıkları bildirilmiştir (Van Lenteren \& Noldus, 1990). Norouzi et al. (2008), İran'da yapmış olduğu bir çalışmada, etrafta diğer konukçular (antepfıstığı, hurma, badem, incir v.d.) olduğu halde, Harnup Güvesi'nin ilk tercihinin nar bitkisi olduğunu belirtmiştir. Araştırıcılar, nar meyvesinin, böceğin yumurta koyma, yumurtadan çıkan larvanın meyve içine rahat girmesi ve burada beslenmesi bakımından Harnup Güvesi tarafından daha çok tercih edildiğini belirtmiştir. Aynı araştırıcılar, nar üzerinde birkaç döl veren Harnup Güvesi'nin, daha sonra antepfıstıklarına, olgunlaşmaya başlayan hurma ve incir meyvelerine zarar vermeye başladığını bildirmiştir.

Zare et al. (2013) ise İran'da yetiştirilen Malas daneh siah, Gabri ve Shahvar isimli üç nar çeşidi üzerinde $A$. ceratoniae'nin biyolojik özellikleri ve yaşam tablosu parametrelerini incelemişlerdir. Araştırıcılar, üç çeşit ile beslenen Harnup Güvesi'nde incelemiş oldukları birçok biyolojik ve yaşam tablosu parametreleri bakımından Malas daneh siah nar çeşidinin, diğer çeşitlere göre daha az uygun olduğunu belirlemişlerdir. Aynı araştırıcılar, Harnup Güvesi'nin üremesi ve çoğalma hızı bakımından Shahvar nar çeşidinin en uygun besin kaynağı olduğunu tespit etmişlerdir. Bu sonuçlar da, yapılan bu çalışmaya paralel olarak zararlının aynı şartlarda farklı sebeplerden dolayı farklı nar çeşitlerini tercih edebileceğini göstermiştir.

Sonuç olarak, çeşitlerin Harnup Güvesi tarafından daha az tercih edilme ve verim özellikleri birlikte düşünüldüğünde, en iyi çeşitlerin Hicaznar ve Mayhoş I olduğu bu çalışma ile belirlenmiştir. Harnup Güvesi zararının, meyve tadının tatı veya tatıya yakın mayhoş, meyve kabuk renginin sarı veya yeşilimsi sarı tonlarda, meyve kabuk kalınlığının ince olduğu çeşitlerde daha yüksek olduğu belirlenmiştir. Buna karşın ekşi tada sahip, koyu kırmızı, kırmızı veya kırmızıya yakın tonlardaki kabuk renginde olan ve nispeten kalın kabuklu çeşitlerde Harnup Güvesi zararının daha düşük olduğu saptanmıştır. Bu sonuçlardan yola çıkılarak, ıslah çalışmalarında bu özelliklere yer verilmeli ve Harnup Güvesi zararının yüksek olduğu yerlerde, üreticiler uygun çeşitlere yönlendirilmelidir.

\section{Yararlanılan Kaynaklar}

Ak, B.E., A. İkinci, A.I. Özguven \& C. Yılmaz, 2009. "Some pomological traits of different pomegranate varieties grown in Sanliurfa-Turkey". Proceedings of the First International Symposium on Pomegranate and Minor Mediterranean Fruits. Acta Hort. (ISHS) 818:115-120.

Al-Izzi, M.A.J., S.K. Al-Maliky, M.A. Younis \& N.F. Jabbo, 1985. Bionomics of Ectomyelois ceratoniae (Zell.) (Lep.: Pyralidae) on pomegranate in Iraq. Environmental Entomology, 14: 149-153.

Anonymous, 2012a. Türkiye Nar Üretimi. (Web sayfası: http://www.tuik.gov.tr.) (Erişim tarihi: Ekim 2013).

Anonymous, 2012b. (Web sayfası: http://www.ttsm.gov.tr/TR/belge/1-177/meyve-ve-asma-cesit-listesi) (Erişim tarihi: Kasım 2013).

Arutyunyan, R.G., 1990. Morfological differences in Pyraloidea (Lep.: Phycitidae). Biologicheskii Zhurnal Armenii, 41 (8): $681-686$.

Avidov, Z. \& S. Gothilf, 1960. Observation on the Honeydew Moth [Crytoblabes gridiella (Mill.)] in Israel. Ktavim, 10 (3-4): 109-124. 
Balachowsky, A. S., 1972. Entomologie appliquee A L'agriculture. Tome II Lepidopterres, Deuxieme Volume. Masson at Editeurs, Paris, $1634 \mathrm{pp}$.

Echlin, T.D., 1982. Carob Moth in California: New state record. California Department of Food and Agriculture, Memo, Nov. 26.

Gothilf, S., 1970. The biology of the Carob Moth, Ectomyelois ceratoniae (Zeller) in Israel. III. Phenology on various hosts. Israel Journal of Entomology, $5: 161-170$.

İkinci, A., 2007. Nar yetiştiriciliği. Tarım Türk Dergisi, (7):12-16.

Kashkuli, A. \& E. Eghtedar, 1976. Biology and ecology of Spectrobates ceratoniae (Zell.) (Lep.: Pyralidae) in the province of Fars. Ent. Phyt. Applig., 41: 21-32.

Mamay, 2013. Şanlıurfa İlinde Nar Bahçelerinde Harnup Güvesi [Apomyelois ceratoniae Zell. (Lepidoptera: Pyralidae)]'nin Popülasyon Gelişimi ve Bulaşıklık Oranının Belirlenmesi ile Mücadelesinde Çiftleşmeyi Engelleme (Mating Distruption) Tekniği'nin Kullanılması. Harran Üniversitesi Fen Bilimleri Enstitüsü, Doktora Tezi, Şanlıurfa, $146 \mathrm{~s}$.

Mart, C., 1992. Güneydoğu Anadolu Bölgesi'nde Nar (Punica granatum L.)'larda Zararlı Harnup Güvesi, Ectomyelois ceratoniae (Zell.) (Lep.: Pyralidae)'nin Bio-Ekolojisi ve Mücadelesi Üzerinde Araştırmalar. Ankara Üniversitesi Fen Bilimleri Enstitüsü, Doktora Tezi, Ankara, $131 \mathrm{~s}$.

Mart, C. \& N. Kılınçer, 1993. Güneydoğu Anadolu Bölgesi narlarında zararlı Harnup Güvesi, Ectomyelois ceratoniae (Zell.) (Lep.: Pyralidae)'nin popülasyon değişimi ve döl sayısı. Türk Entomoloji Dergisi, 17 (4): 209-216.

Mart, C. \& Kılınçer, N., 1994. "Harnup güvesi Ectomyelois ceratoniae (Zell.) (Lepidoptera: Pyralidae) ile mücadelede biyolojik preparatların etkinliklerinin kimyasal ve mekanik mücadele yöntemleri ile karşılaştırılması, 511-518". Türkiye 3. Biyolojik Mücadele Kongresi (25-28 Ocak 1994), İzmir.

Mehrnejad, M. R., 1993. Biology of the Carob Moth Ectomyelois ceratoniae: A new pest of pistachio in Rafsanjan. Applied Entomology and Phytopathology, 66 (1-2): 1-12.

Mozaffarian, F., M. Mardi, A. Sarafrazi \& G. Nouri Ganbalani, 2007a. Assessment of geographic and host-associated population variations of the Carob Moth, Ectomyelois ceratoniae, on pomegranate, fig, pistachio and walnut, using AFLP markers. Journal of Insect Science, 8(6): 1-11.

Mozaffarian, F., A. Sarafrazi \& G. Nouri Ganbalani, 2007b. Host plant associated population variation in the Carob Moth Ectomyelois ceratoniae in Iran: A geometric morphometric analysis suggests a nutritional basis. Journal of Insect Science, 7: 1536-2442.

Norouzi, A., A. A. Talebi \& Y. Fathipour, 2008. Development and demographic parameters of the Carob Moth Ectomyelois ceratoniae on four diet regimes. Bulletin of Insectology, 61 (2): 291-297.

Onur, C., 1988. Nar (Özel Sayı). Derim, 5(4).

Onur, C., H. Tibet \& E. A. Işık, 1999. "Melezleme yoluyla nar (Punica granatum L.) çeşit ıslahı, 58-61". Türkiye III. Ulusal Bahçe Bitkileri Kongresi (14-17 Eylül 1999), Ankara.

Özgüven A.I. \& C. Yılmaz, 2000. Pomegranate growing in Turkey. Options Mediterraneennes, Serie A: Seminaires Mediterraneannes. 42: 41-48.

Özgüven, A.l., S. Çetiner, B.E. Ak \& C. Yılmaz, 1997. Güneydoğu Anadolu Bölgesinde Değişik Nar Çeşitlerinin Adaptasyonu Üzerinde Araştırmalar (II. Araştırma Dilimi). Ç.Ü. Ziraat Fakültesi Genel Yayın No: 192, GAP Yayınları No: 112, Adana, $29 \mathrm{~s}$.

Öztop, A., M. Keçeci \& M. Kıvradım, 2010. Antalya ilinde nar zararlıları üzerine araştırmalar: Gövde ve dallarda zarar yapanlar. Derim, 27(1):12-17.

Öztürk, N. \& M. R. Ulusoy, 2009. Pests and natural enemies determined in pomegranate orchards in Turkey. I. Int. symposium on pomegranate and minor mediterranean fruits, 16-19 October 2006, Adana-Turkey. Acta Horticulturae, 818: 277-284.

Öztürk, N. \& M. R. Ulusoy, 2011. Doğu Akdeniz Bölgesi nar bahçelerinde Harnup Güvesi [Ectomyelosi ceratoniae Zell. (Lepidoptera: Pyralidae)]'nin ergin popülasyon değişimi. Türk. Entomol. Bült., 1 (2): 109-118.

Öztürk, N., M. R. Ulusoy \& E. Bayhan, 2005. Doğu Akdeniz Bölgesi nar alanlarında saptanan zararlılar ve doğal düşman türleri. Türk Entomoloji Dergisi, 29 (3): 225-235.

Polat, H. \& T. Özer, 2000. Harran Ovası'nda Yetiştirilebilecek Nar Çeşitleri. T.C. Başbakanlık Köy Hizmetleri Genel Müdürlüğü Şanlıurfa Araştırma Enstitüsü Müdürlüğü Yayınları, Şanlıurfa, 13s. 
Harnup güvesi [Apomyelois (=Ectomyelois) ceratoniae Zeller (Lepidoptera: Pyralidae)]'nin farklı nar çeşitlerindeki bulaşıklık oranı ve konukçu tercihi

Tokmakoğlu, C., O. Z. Soylu \& H. Devecioğlu, 1967. Ectomyelois ceretoniae (Zell.)'in biyolojisi ve mücadele metotlar üzerinde araştırmalar. Bit. Kor. Bült., 7 (3): 91-106.

Toledo, J. \& E. Albujer, 2005. Project of Technical standards for pomegranate integrated production in Valencia. http://ressources.ciheam.org (Erişim tarihi: Ocak 2010).

Uzun, M., S. Atlı, S. Arpacı \& A. Akgün, 2007. Bazı Nar Çeşit ve Tiplerinin Gaziantep Yöresine Adaptasyonu. T.C. Tarım ve Köyişleri Bakanlığı Tarımsal Araştırmalar Genel Müdürlüğü Antepfıstığı Araştırma Enstitüsü Müdürlüğü, Yayın no: 36, 18 s.

Van Lenteren, J. C. \& L.P.J.J., Noldus, 1990. "Whitefly-Plant Relationships: Behavioural and Ecological Aspects, 4789". In Whiteflies: Their Bionomics. Pest Status and Management (Ed.: D. Gerling), Intercept Ltd, Andover UK..

Yazıcı, K. \& A. Şahin, 2012. Narın Dünya ve Türkiye'deki Yeri ve Önemi. (Web sayfası: www.batem.gov.tr/haber/haftalar/nar_dunya_tur.pdf) (Erişim Tarihi: Ekim, 2013).

Yılmaz, M., A.I. Özgüven, B.E. Ak, \& S. Çetiner, 1993. Güneydoğu Anadolu Bölgesinde Değişik Nar Çeşitlerinin Adaptasyonu. Ç.Ü. Ziraat Fakültesi Genel Yayın No: 57, GAP Yayınları No: 72, Adana, 22 s.

Zare, D., J.J. Sendi, A.J. Nodoushan \& R. Khosravi, 2013. Life table parameters and biological characteristics of Ectomyelois ceratoniae Zeller (Lepidoptera: Pyralidae) on three cultivars of pomegranate. Archives of Phytopathology and Plant Protection, 46 (7): 766-773. 